\title{
Nitric oxide synthase 2 (NOS2) expression in histologically normal margins of oral squamous cell carcinoma
}

\author{
Rosana Morelatto ${ }^{1}$, María-Elina Itoiz ${ }^{2}$, Natalia Guiñazú ${ }^{3}$, Daniel Piccini ${ }^{4}$, Susana Gea ${ }^{5}$, Silvia López-de Blanc ${ }^{6}$ \\ ${ }^{1}$ DDS, PhD Assistant Professor, Clinical Stomatology “B”. School of Dentistry National University of Cordoba \\ 2 DDS, PhD Emeritus Professor, School of Dentistry, University of Buenos Aires \\ ${ }^{3}$ DCS, PhD Assistant Professor. Department of Chemical Biochemistry. School of Chemical Sciences. National University of \\ Cordoba \\ ${ }^{4}$ DMS, PhD Head Professor, Pathology Service. School of Medicine. National University of Cordoba \\ ${ }^{5}$ DCS, PhD Associated Professor, Department of Chemical Biochemistry. School of Chemical Sciences. National University of \\ Cordoba \\ ${ }^{6}$ DDS, PhD Head Professor. Clinical Stomatology “B”. School of Dentistry. National University of Cordoba, Cordoba. \\ Argentina
}

Correspondence:

Departamento de Patología Oral

Facultad de Odontología

Pabellón Argentina

Ciudad Universitaria, Agencia 4

(5016) Córdoba

República Argentina

rmorelatto@gmail.com

\author{
Morelatto R, Itoiz ME, Guiñazú N, Piccini D, Gea S, López-de Blanc \\ S. Nitric oxide synthase 2 (NOS2) expression in histologically normal \\ margins of oral squamous cell carcinoma. Med Oral Patol Oral Cir Bucal. \\ 2014 May 1;19 (3):e242-7. \\ http://www.medicinaoral.com/medoralfree01/v19i3/medoralv19i3p242.pdf

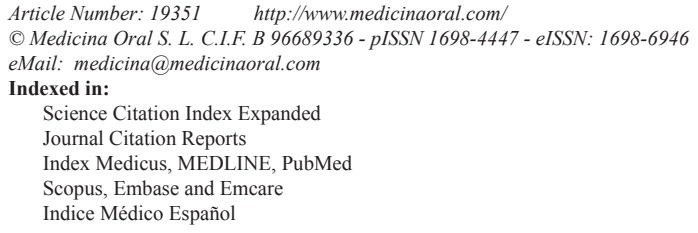

\begin{abstract}
The activity of Nitric Oxide Synthase 2 (NOS2) was found in oral squamous cell carcinomas (OSCC) but not in normal mucosa. Molecular changes associated to early carcinogenesis have been found in mucosa near carcinomas, which is considered a model to study field cancerization. The aim of the present study is to analyze NOS2 expression at the histologically normal margins of OSCC.

Study Design: Eleven biopsy specimens of OSCC containing histologically normal margins (HNM) were analyzed. Ten biopsies of normal oral mucosa were used as controls. The activity of NOS2 was determined by immunohistochemistry. Salivary nitrate and nitrite as well as tobacco and alcohol consumption were also analyzed. The Chi-squared test was applied.

Results: Six out of the eleven HNM from carcinoma samples showed positive NOS2 activity whereas all the control group samples yielded negative ( $p=0.005$ ). No statistically significant association between enzyme expression and tobacco and/or alcohol consumption and salivary nitrate and nitrite was found.

Conclusions: NOS2 expression would be an additional evidence of alterations that may occur in a state of field cancerization before the appearance of potentially malignant morphological changes.
\end{abstract}

Key words: Field cancerization, oral squamous cell carcinoma, Nitric Oxide Synthase 2 (NOS2), malignity markers. 


\section{Introduction}

Despite the fact that the oral cavity is an accessible location for medical examination, most cases of oral cancer (OC) are detected at advanced stages, which is the reason for the low survival rates recorded. OC has high morbidity rates, with an overall survival rate of $34-56 \%(1,2)$. In Cordoba, Argentina, mortality rates have increased noticeably in females, $77 \%$ for the period 1975-2000 (3). These tendencies probably indicate a change in women's habits, such as increase in smoking and alcohol drinking (4-6). In a previous study, we found that late diagnosis is mainly due to professional delay in indicating a biopsy (7). Locoregional recurrence is the main reason for the failure of head and neck cancer treatments. Failure is associated to the remaining cancer cells in the surgical margins that are considered negative in the pathologically examined sample (8). This could be explained a lack of sensitivity of the method used to identify cells that have already started their malignity transformation and have not yet developed a pathological phenotype. Besides Slaughter et al. introduced the concept of "field cancerization" to explain the increased risk of malignant transformation in large areas of the epithelial lining of the upper aerodigestive tract, modified by tobacco and alcohol consumption (9). This hypothesis was based on the high incidence of second primary tumors or multifocal cancer and was proved by the demonstration of molecular changes in clinically healthy mucosa of smoking patients $(10,11)$. Furthermore, the sequential or simultaneous development of oral premalignant and/or malignant lesions in a single patient evidences progressive genotypic and phenotypic alterations associated to field cancerization (12). The search for markers of field cancerization before the appearance of premalignant morphological alterations is of biological interest and clinically relevant in terms of early diagnosis and OC prevention. We have tried to detect a field cancerization by means of immunohistochemical (IHC) reactions, easy to apply to routine biopsic material (13-16).

Nitric oxide (NO) is a small, relatively stable, free radical gas, found both in normal and in malignant tissues $(17,18)$. It is synthesized by nitric oxide synthases (NOS) which exists in three different isoforms: neuronal NOS (NOS1), endothelial NOS (NOS3), and inducible NOS (NOS2). Lipopolysaccharide, interferon and numerous other factors induce NOS2 expression in endothelial and inflammatory cells $(19,20)$. NOS2 is also expressed in some normal epithelia such as airway epithelium, basal keratinocyte layer of normal skin, and normal salivary ducts (21). Neither NOS2 protein nor mRNA was found in normal oral mucosa (22). Neoplastic tissues, including head and neck carcinomas, over-express the enzyme. NOS2 has been involved in tumor growth, mutagenicity, angiogenesis and metastasis $(23,24)$. NOS2 activity was also found in oral epithelial dysplasia, submucous fibrosis and verrucous hyperplasia (25).

Considering that alterations associated to field cancerization have been found in normal epithelia near oral carcinomas $(11-14,16)$, the present study focuses on the evaluation of the NOS2 expression in these areas as another biomarker for risk of malignant transformation. Since NOS2 enzyme intervenes in NO synthesis and given the fact that NO is highly reactive, saliva levels were determined by measuring nitrate and nitrite, which are the NO oxidation products $(26,27)$.

\section{Material and Methods}

Tissue sources:

Out of eleven biopsy and/or excised surgical archive specimens of oral squamous cell carcinomas (OSCC), only samples involving histologically normal oral mucosa were selected, provided they were situated at more than $5 \mathrm{~mm}$ away from the tumor without or with very mild inflammatory infiltrate.

Ten specimens of clinically and histologically normal oral mucosa obtained during surgery for deep seated benignant lesions were selected as control group (CG). All the samples belonged to patients attending the Oral Pathology Department, Facultad Odontología, Universidad Nacional de Córdoba. All the cases included presented complete clinical records and saliva complementary studies, as well.

Exclusion criteria were pregnancy, use of vitamin supplements, antibiotics or anti-inflammatory agents, and previous oncological treatment.

Due to the well known influence of tobacco and alcohol in the development of a sub-clinic level of field cancerization, patients with a history of more than 200000 cigarettes or with more than $50 \mathrm{~g}$ of alcohol per day were discarded (28).

A complete clinical record included the following data: Clinical stage of patients: According to the Union for International Cancer Control (UICC) criteria, stages III and IV were defined as advanced tumors and stages I and II as early ones (29).

Tobacco consumption: The total number of cigarettes smoked during the patient's lifetime was estimated according to Zanetti et al. method (30), multiplying the number of cigarettes smoked per year by the number of years. Patients were categorized as: non-smokers (never having smoked), or smokers (having smoked more than 100,000 cigarettes).

Alcohol consumption: one alcoholic unit per day $(1 \mathrm{U}=$ 8 to $10 \mathrm{~g}$ of ethanol $=1$ glass of wine $=1 / 4$ liter of beer $=1$ measure of spirits) was considered alcohol exposure according to Pentenero et al. 2008 (31). The total alcohol intake was estimated considering the grams per day thus obtaining the approximate lifetime alcohol consumption. Patients were categorized according to 
their consumption as: non-drinkers (never having drunk) and drinkers (having consumed more than 100,000 g). Concentration of nitrate and nitrite in saliva samples: Samples were obtained and processed following laboratory standardized conditions.

Nitrite levels were considered low or high according to whether concentrations were lower or higher than 100 $\mu \mathrm{M}$ respectively, while nitrate levels were considered low or high according to whether concentrations were lower or higher than $800 \mu \mathrm{M}$, respectively.

Immunohistochemistry: Sections of $7 \mu \mathrm{m}$ thick were obtained; endogenous peroxidase was blocked by immersion in $0.5 \%$ methanolic peroxide for $15 \mathrm{~min}$. Antigen retrieval was performed with Citra (Biogenex) in 3 cycles of 4 minutes each, at $400 \mathrm{~W}$ microwaves. The sections were then incubated overnight with the primary antibody (anti-NOS2, C-terminal, rabbit, Cat. sc-651, Santa Cruz Biotechnology, Inc.), diluted 1:50 in PBS in a humid chamber at $4^{\circ} \mathrm{C}$. Antibody binding sites were visualized using a streptavidin-peroxidase detection kit (Kit Multilink, Biogenex). Slides with and without hematoxylin counterstain were mounted. As positive control a section of a single block of apical granuloma was included in each staining batch, rendering highly positive for NOS2. As negative control for antibody specificity tissue samples were included in which the primary antibody was omitted.

The presence of brown precipitate in the cytoplasm was considered positive provided it could be clearly distinguished from the negative reaction of the nucleus in preparations without counterstaining.

In each case the staining intensity was evaluated by comparing it with the respective positive control of the same staining batch. A reaction evident but less intense than the control, was considered mildly positive; while a reaction similar or higher than the control, was considered positive or highly positive respectively. In the present study the tumor epithelial cords and their histologically normal margins were grouped in positive $(+)$ or negative $(-)$, independently from the intensity of the reaction. Two oral pathologists, who ignored the clinical data, evaluated the immuno-histochemical assays.

Statistical analysis: A Chi Square test was applied to evaluate the differences in NOS2 expression, between the histologically normal margins of OSCC and the control group, and between tobacco and alcohol consumption and salivary nitrate and nitrite concentrations.

\section{Results}

Sample features:

In this cross-sectional study 21 samples were examined: 11 OSCC samples corresponding to the study group and 10 samples as control group. No statistically significant association was found regarding tobacco and alcohol consumption in both groups. Table 1 shows the characteristics of the included cases.

NOS2 citoplasmatic expression in OSCC

NOS2 activity is expressed in the cellular cytoplasm

Table 1. Characteristics of the study and control group.

\begin{tabular}{|l|c|c|c|}
\hline Characteristics & $\begin{array}{c}\text { Study } \\
\text { Group (\%) }\end{array}$ & $\begin{array}{c}\text { Control } \\
\text { Group (\%) }\end{array}$ & \multicolumn{1}{|c|}{ p $^{*}$} \\
\hline Samples(n) & $11(52)$ & $10(48)$ & - \\
\hline Sex & & & - \\
\hline female & $4(36)$ & $8(80)$ & - \\
\hline male & $7(64)$ & $2(20)$ & - \\
\hline Age & & & - \\
\hline mean & 63 & 52 & \\
\hline range & $51-77$ & $34-82$ & \\
\hline Tobacco consumption(n) & & & \\
\hline yes & $9(82)$ & $5(50)$ & 0,12 \\
\hline no & $2(18)$ & $5(50)$ & \\
\hline Alcohol consumption(n) & & & \\
\hline yes & $9(82)$ & $6(60)$ & 0,27 \\
\hline no & $2(18)$ & $4(40)$ & \\
\hline Nitrite (uM) & & & \\
\hline high & $6(55)$ & $5(50)$ & 0,84 \\
\hline low & $5(45)$ & $5(50)$ & \\
\hline Nitrate (uM) & & & \\
\hline high & $3(27)$ & $6(60)$ & 0,13 \\
\hline low & $8(73)$ & $4(40)$ & \\
\hline NOS2** & & & \\
\hline positive & $6(54)$ & & 0,005 \\
\hline negative & $5(46)$ & $10(100)$ & \\
\hline
\end{tabular}

- Chi square test.

** Histologically normal margins of oral squamous cell carcinoma. 
as a diffuse precipitate without any nucleous reaction. Carcinoma reactivity does not differ from the existing one in the literature (32). A different intensity reaction was observed in the OSCC epithelial cords, in the stroma inflammatory infiltrate and in the vascular endothelium (Fig. 1).

Histologically normal mucosa of the tumor margins showed reactions ranging from negative to positive expressions in all epithelial layers (Fig. 2). Six out of the 11 cases under study were positive while in the CG the epithelium was negative for NOS2 reaction in all

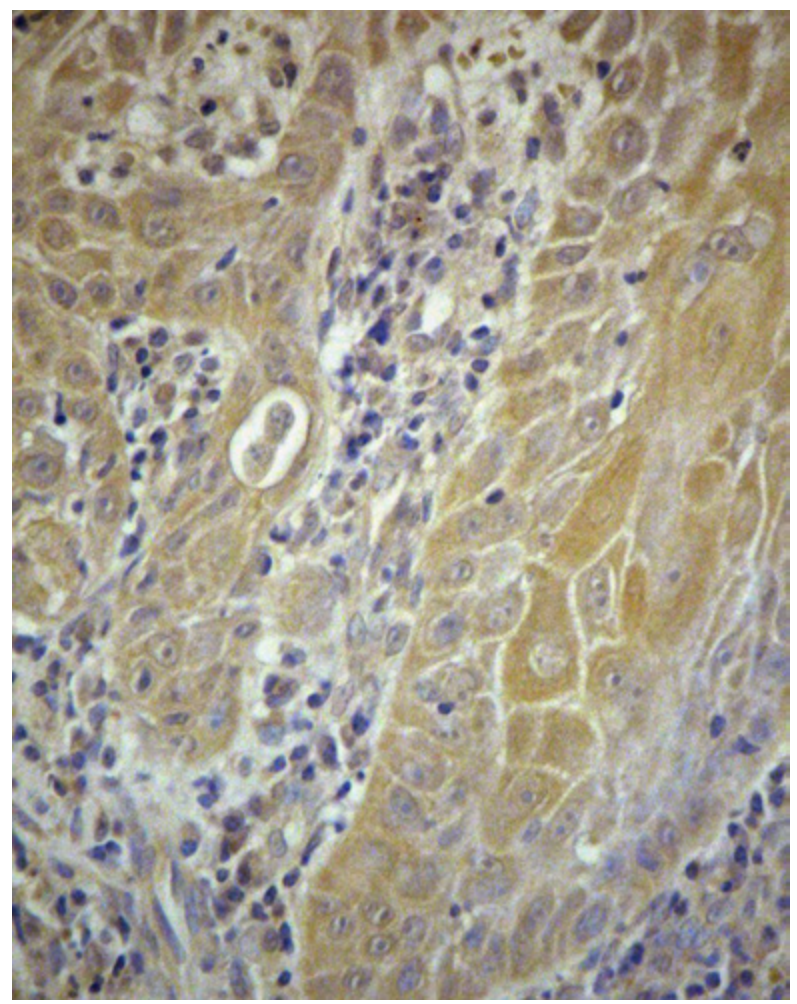

Fig. 1. Immunohistochemical expression of NOS2 in epithelial cords of OSCC. Haematoxilin counterstain (x25).

cases $(p=0.005)$. The Odds Ratio (OR) could not be calculated since the control group did not express NOS2 in any sample; therefore, the corresponding frequency was zero (0).

Only a moderate NOS2 expression in the connective tissue was found in both groups whenever isolated inflammatory cells were present.

Tables 2 and 3 show the characteristics of the NOS2 expression in study and those of the control group, respectively.

Nitrite and nitrate levels

The salivary nitrate and nitrite levels were similar both in carcinoma and control groups (see Table 1).

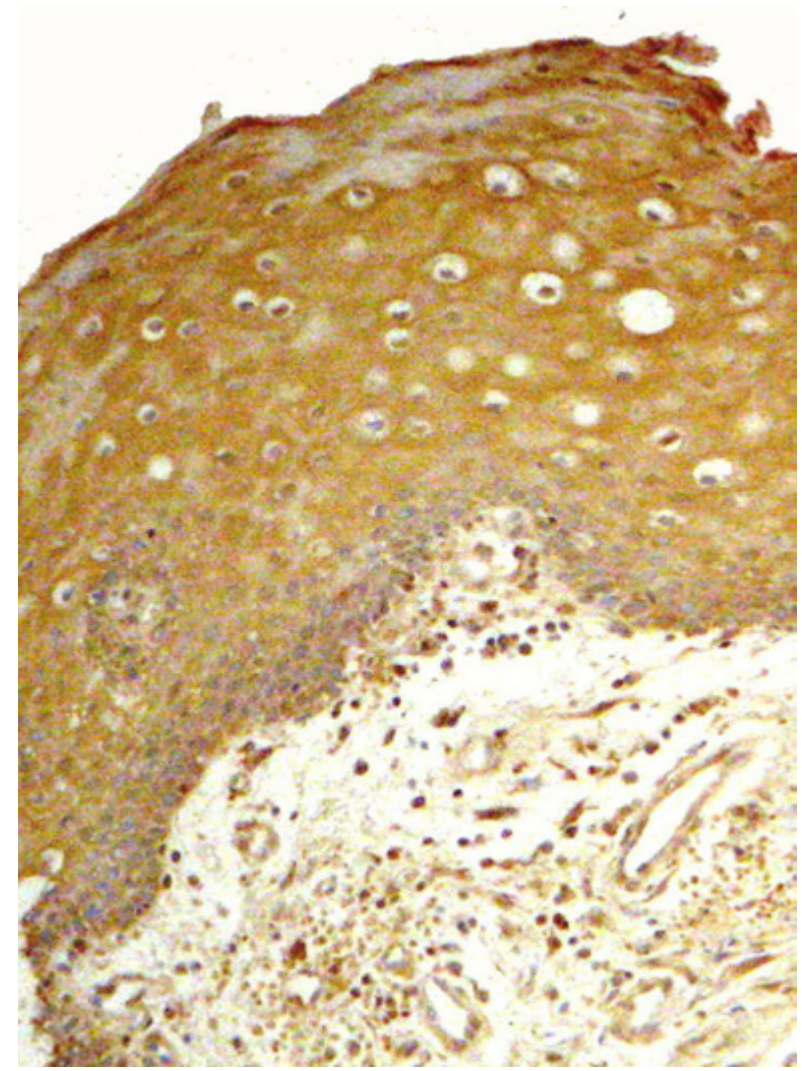

Fig. 2. NOS2 expression in histologically normal margins of OSCC. Endothelial and inflammatory cells were also positive (x10).

Table 2. Study Group (OSCC): NOS2 expression, tumor stage and location.

\begin{tabular}{|c|c|c|c|c|}
\hline Sample & $\begin{array}{c}\text { NOS2 } \\
\text { tumor }\end{array}$ & $\begin{array}{c}\text { NOS2 } \\
\text { (NTEB)* }\end{array}$ & Location & Stage \\
\hline 1 & $(+)$ & $(-)$ & oropharynx & advanced** \\
\hline 2 & $(+)$ & $(+)$ & alveolar ridge & early \\
\hline 3 & $(+)$ & $(+)$ & alveolar ridge & early \\
\hline 4 & $(+)$ & $(-)$ & tongue & early \\
\hline 5 & $(-)$ & $(-)$ & lengua & early \\
\hline 6 & $(+)$ & $(+)$ & floor of mouth & advanced** \\
\hline 7 & $(+)$ & $(+)$ & cheek & early \\
\hline 8 & $(-)$ & $(+)$ & alveolar ridge & early \\
\hline 9 & $(-)$ & $(+)$ & tongue & advanced** \\
\hline 10 & $(+)$ & $(-)$ & gum & advanced** \\
\hline 11 & $(-)$ & $(-)$ & floor of mouth & advanced** \\
\hline
\end{tabular}

* histologically normal margins of oral squamous cell carcinoma.

** All the patients diagnosed at advanced stage had nodes (N).

\section{Discussion}

Tumor epithelial cords were positive for NOS2; the degrees of expression were variable, in agreement with previous studies (32). Activation of NOS2 has also been demonstrated in lung, colon and prostate cancer and in melanoma (25,33-36) and has been related to cervical lymph node metastasis and to greater metastatic potential $(25,32)$. Over-expression of NOS2 
Table 3. Control Group: NOS2 expression, lesion and location.

\begin{tabular}{|c|c|c|c|}
\hline Sample & NOS2 * & Lesion & Location \\
\hline 1 & $(-)$ & condyloma acuminatum & hard palate \\
\hline 2 & $(-)$ & fibrous hyperplasia & cheek \\
\hline 3 & $(-)$ & fibrous hyperplasia & cheek \\
\hline 4 & $(-)$ & fibrous hyperplasia & tongue border \\
\hline 5 & $(-)$ & fibrous hyperplasia & cheek \\
\hline 6 & $(-)$ & fibrous hyperplasia & cheek \\
\hline 7 & $(-)$ & fibrous hyperplasia & cheek \\
\hline 8 & $(-)$ & fibrous hyperplasia & cheek \\
\hline 9 & $(-)$ & fibrous hyperplasia & cheek \\
\hline 10 & $(-)$ & fibrous hyperplasia & cheek \\
\hline
\end{tabular}

*Histologically normal margins.

has been found in dysplasia specimens $(17,33,37)$ and has also been involved in early cellular changes leading to malignity such as transformation of normal cells or growth of altered cells (36).

The present study not only analyzed NOS2 expression in tumor tissues but also demonstrated its activity in the surrounding normal tumor epithelium. This is the first time in which a NOS2 remarkable expression is reported for the histologically normal mucosa surrounding carcinomas. In these still morphologically unaltered areas, genetic and histochemical alterations typical of a field cancerization have been proven $(9,10)$.

Since NOS2 expression is triggered by inflammatory reactions, and with the aim of determining if its expression in OSCC normal margins is independent from the inflammatory response, we only included samples bearing the inevitable presence of some isolated inflammatory cells in both study and control groups. The strict inclusion criteria limited the number of samples available.

It is well known that the sum of genetic alterations lead to gradual phenotypic changes. In this work, some positively stained tumors turned out to have negative margins. Conversely, some negative tumors were found to have positive margins. The complexity and the heterogeneity of the NOS2 expression in tumors and within a same tumor has been found in the literature (36); the same finding was reported when other cancerization markers have been used $(12,15)$. It has been suggested that NOS2, which is over expressed in transformed cells, can mediate endothelial proliferation through $\mathrm{NO}$ which, in turn, acts as a cellular signal for angiogenesis (25). We found an increased NOS2 expression in the OSCC endotelial cells. Interestingly, we had previously demonstrated a rise in sub-epithelial capillaries of dysplastic leukoplakia, non-invasive margins of carcinoma (15) and oral mucosa of alcoholic patients (16). Moreover, NO has been suggested to modulate different cancer-related events including angiogenesis, apoptosis, cell cycle, invasion and metastasis (20). The anti-tumoral NO effects described in other research works stimulates apoptosis and inhibit angiogenesis
$(17,18,38)$, although further clinical studies of cancer patients are still necessary. The biological activity of NO depends on variables such as the originating source, its local concentration, tumor microenvironment and spatial and temporal constants that may determine the ON function.

More studies are necessary to establish the role of the path ON/NOS2 in tumor genesis and evolution and to determine the usefulness of NOS2 inhibitors as chemoprevention medication $(39,40)$.

The levels of salivary nitrite and nitrate were measured looking for their relationship with the expression of NOS2 in patients with tumors. No differences were found with the control group. Taking into account the fact that nitrite concentration in saliva is associated with age, diet composition, fungal or bacterial infection and with tobacco and alcohol consumption, we find it important to continue enlarging our sample in the search for a possible association.

NOS2 expression in clinically and histologically normal mucosa would be an additional evidence of the alterations that may occur in a field of cancerization before potentially malignant morphological changes appear.

This preliminary data suggest that the expression of NOS2 could be useful for the diagnosis of "field cancerization" or "at risk mucosa" in those patients exposed to risk factors like excessive tobacco and alcohol consumption but who have not yet evinced lesions in the oral mucosa.

\section{References}

1. Hollows P, Mc Andrew PG, Pierini MG. Delays in the referral and treatment of oral squamous cell carcinoma. $\mathrm{Br}$ Dent $\mathrm{J}$. 2000;188:262-5.

2. Jones AS, Beasley N, Houghton D, Husband DJ. The effects of stage on survival and other parameters in squamous cell carcinoma of the oral cavity, pharynx and larynx. Clin Otolaryngol Allied Sci. 1998;23:51-6.

3. Morelatto RA, López de Blanc SA. Oral cancer mortality in the province of Cordoba, Argentine Republic in the period 1975-2000. A comparative study with other populations. Med Oral Patol Oral Cir Bucal. 2006;11:e230-5.

4. La Vecchia C, Lucchini F, Negri E, Levi F. Trends in oral cancer mortality in Europe. Oral Oncol. 2004;40:433-9.

5. Macfarlane GJ, Evstifeeva TV, Robertson C, Boyle P, Scully C. Trends of oral cancer mortality among females worldwide. Cancer Causes Control. 1994;5:255-8.

6. Boyle P, Leon ME, Maisonneuve P, Autier P. Cancer control in women. Update 2003. Int J Gynaecol Obstet. 2003;83 Suppl 1:179202.

7. Morelatto RA, Herrera MC, Fernández EN, Corball AG, López de Blanc SA. Diagnostic delay of oral squamous cell carcinoma in two diagnosis centers in Cordoba, Argentina. J Oral Pathol Med. 2007;36:405-8.

8. Lessa RC, Campos AH, de Freitas CE, da Silva FR, Kowalski LP, Carvalho AL, et al. Identification of upregulated genes in oral squamous cell carcinomas. Head Neck. 2013;35:1475-81.

9. Slaughter DP, Southwick hw, Smejkal W. Field cancerization in oral stratified squamous epithelium; clinical implications of multicentric origin. Cancer. 1953;6:963-8.

10. Brennan JA, Boyle JO, Koch WM, Goodman SN, Hruban RH, 
Eby YS, et al. Association between cigarette smoking and mutation of the p53 gene in squamous cell carcinoma of the head and neck. N Engl J Med. 1995;332:712-7.

11. Braakhuis BJ, Tabor MP, Kummer JA, Leemans CR, Brakenhoff RH. A genetic explanation of Slaughter's concept of field cancerization: evidence and clinical implications. Cancer Res. 2003;63:1727-30.

12. Tabor M, Brakenhoff H, Ruijter-Schippers H, Van Der Wal J, Snow G, Leemans C, et al. Persistence of genetically altered fields in head and neck cancer patients: biological and clinical implications. Clin Cancer Res. 2001;7:1523-32.

13. Schwint AE, Savino TM, Lanfranchi HE, Marschoff E, Cabrini RL, Itoiz ME. Nucleolar organizer regions in lining epithelium adjacent to squamous cell carcinoma of human oral mucosa. Cancer. 1994;73:2674-9.

14. Chimeno Zoth SA, Collet AM, Heber E, Schwint AE, Itoiz ME. Early detection of alterations associated to oral cancer. Acta Odontol Latinoam. 2000;13:100-12.

15. López de Blanc SA, Collet AM, Gandolfo MS, Femopase F, Hernández SL, Tomasi VH, et al. Nucleolar organizer regions (AgNOR) and subepitelial vascularization as field cancerization markers in oral mucosa biopsies of alcoholic and smoking patients. Oral Surg Oral Med Oral Pathol Oral Radiol Endod. 2009;108:74753.

16. Gandolfo $M$, Keszler A, Lanfranchi H, Itoiz ME. Increased subepithelial vascularization and VEGF expression reveal potentially malignant changes in human oral mucosa lesions. Oral Surg Oral Med Oral Pathol Oral Radiol Endod. 2011;111:486-93.

17. Ying L, Hofseth LJ. An emerging role for endothelial nitric oxide synthase in chronic inflammation and cancer. Cancer Res. 2007;67:1407-1410.

18. Shang ZJ, Li JR, Li ZB. Effects of exogenous nitric oxide on oral squamous cell carcinoma: an in vitro study. J Oral Maxillofac Surg. 2002;60:905-10.

19. Lyons CR. The role of nitric oxide in inflammation. Adv Immunol. 1995;60:323-71.

20. Choudhari SK, Chaudhary M, Bagde S, Gadbail AR, Joshi V. Nitric oxide and Cancer: a review. World Journal of Surgical Oncology. 2013;11:118.

21. Brennan PA, Umar T, Zaki GA, Langdo JD, Spedding AV, Buckley $\mathrm{J}$, et al. Are myoephitelial cells responsible for the widespread expression of inducible nitric oxide synthase in pleomorphic adenoma? An immunohistochemical study. J Oral Pathol Med. 2000;29:279-83.

22. Chen YK, Hsuen SS, Lin LM. Expression of inducible nitric oxide synthase in human oral premalignant epithelial lesions. Arch Oral Biol. 2002;47:387-92.

23. Ou Yang KX, Liang J, Huang ZQ. Association of clinicopathologic parameters with the expression of inducible nitric oxide synthase and vascular endothelial growth factor in mucoepidermoid carcinoma. Oral Dis. 2011;17:590-6.

24. Brennan PA, Palacios-Callender M, Zaki GA, Spedding AV, Langdon JD. Type II nitric oxide synthase (NOS2) expression correlates with lymph node status in oral squamous cell carcinoma. J Oral Pathol Med. 2001;30:129-34.

25. Brennan PA, Conroy B, Sinclair D, Spedding A. Expression of inducible nitric oxide synthase and p53 in oral epithelial dysplasia. Oral Surg Oral Med Oral Pathol Oral Radiol Endod. 2000; 90:624-9.

26. Connelly S, Macabeo-Ong M, Dekker N, Jordan R, Schmidt B. Increased nitric oxide levels and iNOS over-expression in oral squamous cell carcinoma. Oral Oncol. 2005;41:261-7.

27. Patel JB, Shah FD, Shukla SN, Shah PM, Patel PS. Role of nitric oxide and antioxidant enzymes in the pathogenesis of oral cancer. JCRT. 2009;5:247-253.

28. Grammatica L, Piepoli S, D’Auria C, Achille G, Marzullo F, Zito FA, et al. Primary tumours neoangiogenesis and P53 expression in oral carcinoma patients. J Exp Clin Cancer Res. 2001;20:225-30.

29. Brouha X, Tromp D, Hordijk GJ, Winnubst J, De Leeuw R. Role of alcohol and smoking in diagnostic delay of head and neck cancer patients. Acta Otolaryngol. 2005;125:552-6.

30. Zanetti R, Rosso S, Martinez C, Navarro C, Schraub S, Sancho Garnier H, et al. The multicentre south European study 'Helios'. I: skin characteristics and sunburns in basal cell and squamous cell carcinomas of the skin. Br J Cancer. 1996;73:1440-6.

31. Pentenero M, Broccoletti R, Carbone M, Corotto D, Gandolfo S. The prevalence of oral mucosal lesions in adults from the Turin area. Oral Dis. 2008;4:356-366.

32. Chen YK, Hsue SS, Lin LM. Increased expression of inducible nitric oxide synthase or human buccal squamous-cell carcinomas: immunohistochemical, reverse transcription-polymerase chain reaction (RT-PCR) and in situ RT-PCR studies. Head Neck. 2002; 24:925-32.

33. Chen YK, Lin LM. Immunohistochemical expression of inducible nitric oxide synthase in DMBA-induced hamster buccal pouch carcinogenesis. Oral Oncol. 2000;36:221-4.

34. Chen WL, Zeng SG, Li HG, Huang HZ, Pan CB. Expression of inducible nitric oxide synthase mRNA in squamous cell carcinoma of tongue. Ai Zheng. 2002;21:314-8.

35. Grimm E, Ellerhorst J, Tang Chi-Hui, Ekmekcioglu S. Constitutive intracellular production of iNOS and NO in human melanoma:possible role in regulation of growth and resistance to apoptosis. Nitric oxide. 2008;9:133-7.

36. Ekmekcioglu S, Ellerhorst J, Smid C, Prieto V, Munsell M, Buzaid A, et al Inducible nitric oxide synthase and nitrotyrosine in human metastatic melanoma tumors correlate with poor survival. Clin Cancer Res. 2000;6:4768-75.

37. Brennan P, Tijjani U, Wilson A, Mellor T. Expression of type 2 nitric oxide synthase and vascular endothelial growth factor in oral dysplasia. J Oral Maxillofac Surg. 2002;60:1455-60.

38. Harada K, Supriatno, Kawaguchi S, Tomitaro O, Yoshida H, Sato M. Overexpression of iNOS gene suppresses the tumorigenicity and metastasis of oral cancer cells. In Vivo. 2004;18:449-55.

39. Aggarwal B, Shishodia S, Sandur S, Pandey M, Sethi G. Inflammation and cancer: How hot is the link? Biochem Pharmacol. 2006;72:1605-21.

40. Fitzpatrick B, Mehibel M, Cowen RL, Stratford IJ. iNOS as a therapeutic target for treatment of human tumors. Nitric Oxide. 2008;19:217-24.

\section{Acknowledgements}

We would like to thank Prof. Ruth Ferreyra for providing samples of positive controls from the archive of Histopathology at the School of Dentistry, UNC. We are grateful to SECYT- UNC for its economic support (Grant and Subsidy). 